\title{
Engaging the Vulnerabilities of Alzheimer's disease: a Care Ethics Perspective
}

\author{
Michael O.S. Afolabi, B.MLS, AMLSCN, C.CE, C.REE, PhD (C) \\ Center for Healthcare Ethics, Duquesne University, Pittsburgh, PA, USA \\ Email: curiousmaik1@vahoo.comafolabim@duq.edu
}

\begin{abstract}
This paper shows that beyond the ethical issues of autonomy and human dignity there some dynamics of vulnerabilities elicited by Alzheimer's disease (AD). It therefore underscores how the ethics of care moral lens offers ethically sensitive ways of engaging the individual and social vulnerabilities of associated with AD. Ultimately, the paper highlights some of the social implications of such an approach.
\end{abstract}

Keywords: Alzheimer's disease; autonomy; care ethics; vulnerability

Introduction \& Background: Beyond its desirable aspects, the global increase in life expectancy heightens the possibility that more people will face debilitating conditions towards the end of their lives. ${ }^{1}$ Such chronic conditions include Alzheimer's disease (AD) and cancers. AD elicits a constellation of issues including memory failures a sense of helplessness with attendant psychological and behavioral sequelae. ${ }^{2}$ Although the burdens of AD occur at the individual, family and social nexus; ${ }^{3}$ its individual layers of burdens are more far reaching in terms of the loss of personality and personhood that increasingly set upon victims of the disease. In this regards, AD foists different degrees of vulnerability on its victims, their family members and the larger society. As such, vulnerability and dependency are key features of those needing long-term care. ${ }^{4}$ Against this conceptual backdrop, this paper examines some of the ethical issues associated with Alzheimer's disease, the different spheres of vulnerability inherent in these, the relevance of a care ethics (CE) perspective in addressing them and some of the implications of such an approach for the care of AD patients.

The Nature and Ethics of Alzheimer's Disease: This section examines the nature of $\mathrm{AD}$ as well as some of the ethical issues it brings to the fore in the context of healthcare.

The Pathophysiology of Alzheimer's disease: Alzheimer's disease is a neurodegenerative, long-lasting pathology which progressively erodes mental capacities, accumulated memories and competencies. ${ }^{5}$ Its underlying biological basis involves processes which facilitate the onset of an insidiously progressive loss of intellectual, cognitive and social capabilities. ${ }^{6}$ It affects multiple cerebral systems and progressively involves more and more brain regions. The resulting cognitive 
deterioration as well as increased impairment in the activities of daily living leads to an increase in patient dependency. ${ }^{7}$ In America, the mortality rate for AD is around 100 , 00 with more than 5 million Americans currently diagnosed. ${ }^{8}$ This is estimated to reach 13 million by $2050 .{ }^{9}$ This prevalence probably reflects what obtains in other industrialized parts of the globe. Some scholars have however suggested that AD may be higher in African countries where the growth of the proportion of elderly persons is generally greater. ${ }^{10}$

$\mathrm{AD}$ is characterized by neurodegenerative alteration in brain architecture brought about by the accumulation of amyloid peptides in brain neural tissue. At the molecular level, the pathogenesis and progression of Alzheimer's disease result from the complex interaction of amyloid on neuroinflammation, cell plasticity and vascular changes. ${ }^{11}$ Although this explanation has been partly challenged on the basis of the discorrelation between amyloid volume and extent of functional brain loss in AD, ${ }^{12}$ the observation that mass destruction of neural tissue does not always give rise to loss of functional capacity negates this. On the other hand, this issue reflects the age-long nosological quandary between the symptoms observed in the clinic and the underlying pathologies demonstrated by medical science. ${ }^{13}$

While the neuronal changes in AD facilitates memory loss, it also fosters loss of intellectual functions. ${ }^{14}$ To be sure, it is estimated that patients with Alzheimer's generally experience a decrease of 2 to 4 points in MME scores (mini-mental state examination). ${ }^{15}$ In the western climate which celebrates autonomy and regards it as perhaps the most authentic reflection of the individual personae, this has far reaching implications in terms of selfhood and perhaps personal conception of dignity. However, there would be some variations in less autonomy-driven climates such as the African Ubuntu or the Asian Confusian contexts. Whereas this suggests how socio-cultural milieu shape the trajectory of the impacts of AD, the ethical themes associated with AD are broadly the same in terms of autonomy, human dignity and dependency.

Autonomy \& Human Dignity in Alzheimer's disease: Chronic conditions including AD highlight different range of ethical issues as opposed to traditional issues associated with curative medicine. ${ }^{16}$ As such they demand a different approach. Indeed, caring in AD specifically elicits a number of ethical issues such as the use of restraints and how to justify these as well as the dilemmas of making sense of patients' agitative and defensive behaviors. ${ }^{17}$ Others include loss of selfhood and/or personhood and the question of dependency and how much of sacrifice may be rightly exacted from family, friends and the larger society. These issues may however be examined in terms of autonomy and human dignity.

As a notion and praxis, autonomy embed self-governance within a climate of respect for others, ${ }^{18}$ as well as integrity, conscientiousness and an inherent capacity for judgment and action. ${ }^{19}$ It thus incorporates the notion of competence - the choice of acceptance or refusal of clinical interventions on the basis of cognitive comprehension ${ }^{20}$ and consequently approximates veridical accounts of a person's preferences. ${ }^{21}$ In $\mathrm{AD}$, the 
increasing decline in cognition implies a corresponding decrease in potential autonomy. This is indeed the norm rather than the exception in AD where decision making capacities, self-awareness and will of patients become significantly diminished. ${ }^{22}$ Although patient autonomy encompasses allowing each patient to choose what interventions they wish to receive, its reciprocal nature and consideration for equal respect for the autonomy of others ${ }^{23}$ suggests the contested and negotiated of autonomy in the care of $\mathrm{AD}$ patients. Hence, patient autonomy in palliative care inevitably involves the professional/clinical judgement of healthcare workers, and depending on context and cultural milieu, the decision making and inputs from family.

On the other hand, the notion of human dignity entails an inherent moral worth of persons by virtue of belonging to the community of human beings. In dementia as in $\mathrm{AD}$, there occurs a gradual and irrevocable loss of everything that makes a person a human being. ${ }^{24}$ This derives largely from the deviation that AD patients increasingly acquire from the "normal" social template of being human. To be sure, patients as well as family are forced into the quandary of dealing with undignifying but characteristic symptoms of AD such as forgetfulness, unwarranted rage, agitation, dysphoria, irritability, delusions and apathy. ${ }^{25}$ To be sure, patients with Alzheimer's disease generally retain consciousness of their dementia ${ }^{26}$ which not only heightens the level of existential suffering but also "harms" their dignity.

Therefore, the moral quandaries associated with AD in relation to loss of autonomy and human dignity underscore some form of vulnerability which the class of patients and their relations friends and care givers experience. The next section engages this theme.

Vulnerability \& Alzheimer's disease: Human vulnerability is both connected to the state of being human and tied to the idea of human finitude. ${ }^{27}$ It is an ontological condition that fosters susceptibility to wounding and suffering from the actions of others. As such, if contextual differences between individuals potentially creates a vulnerable condition, then tangible differences including educational prowess, technological capacities, health conditions, economic clout will engender different types of vulnerabilities for different people. ${ }^{28}$ Alzheimer's disease however presents a special sort of vulnerability in terms of the fragmentation of individual selfhood and autonomous capabilities and an attendant dependency. This section examines the individual and social dynamics of this vulnerability.

Individual Vulnerability in Alzheimer's Disease: Healthcare represents an instinctual and institutional response to the changing tides of health and sickness. Hence, patienthood entails some degree of contextual vulnerability. If this is true, the degree of vulnerability will vary from sickness to sickness, and for diseases such as Alzheimer's disease the extent will be high. In this vein, patients with AD often suffer shame and insecurity of the uncertainty of appearing demented to others as well as proper social and physiological functioning. This fosters a growing awareness and need 
for dependency on others and partly shapes the likelihood of their lapsing into bouts of anger, depression and deceptive behaviors. ${ }^{29}$ Indeed, Patients with AD are susceptible to delusions most often present in the form of beliefs of theft and infidelity, and visual hallucinations of people from the past, or of intruders. ${ }^{30}$

The unbearable suffering associated with AD partly underscores how the loss of autonomy and the need to relieve suffering make patients vulnerable to exploring desperate solutions such as euthanasia which is spurred by medical, social and psychological suffering of unbearable proportions. ${ }^{31}$ One of the paradoxes associated with this involves the relationship between individual autonomy and the relief of suffering as a justifying lens and the increasingly smaller options of good death that become open to patients ${ }^{32}$ once requests or euthanasia in the context of AD become the norm. For Gordijn, the three possible scenarios involve incompetent patients, competent patients and incompetent patients with advance directives. ${ }^{33}$ However, the common threads to these is vulnerability.

Another kind of contextual vulnerability inherent in AD relates to the symptoms of the condition. The susceptibility of patients to falls and aggressive and self-hurting behaviors exemplifies this. Being aware of this while unable to address the situation obviously constitutes a source of suffering and pain to patients, in terms of diminished intactness and personhood. ${ }^{34}$ The medical nature of this kind of vulnerability underscores not only the need for dependency on others generally but also the importance of clinical intervention in particular.

Social Vulnerability in Alzheimer's Disease: Patients and relatives are central actors in palliative care and often need to work together with healthcare providers ${ }^{35}$ to choose $^{2}$ meaningful options from the range of available interventions. This also holds true for AD contexts where the societal burden of the attendant dementia is substantial and increasing, and patients and their caregivers are faced with a range of physical and psychosocial needs. ${ }^{36}$ Also, family members deal with a physically and mentally deteriorating disorder which rob their loved ones of individuality and autonomy. ${ }^{37}$ As such, there is a social dynamics to the vulnerability inherent in AD.

Alzheimer's patients die before their time, but they do not die alone. Bennahum captures this by stating that "the family is bereaved while the patient still lives, and that is terribly difficult to bear". ${ }^{38}$ In other words, family and friends of AD patients suffer a constellation of psycho-social pains in watching their loved one irreversibly deteriorate, lose their memory and cognitive functions. Perhaps, even more grueling is the fact that such suffering can only go away if the patient die. Hence, AD presents as a form of double tragedy in terms of the pre-death suffering that families and close associates go through as well as the loss that occurs following eventual death. It is reported, for instance, that some family members of AD patients engage the vulnerability to pain to which they are subject by denying the close ties they have to such patients. A daughter of an AD patient was quoted as saying: "she is not my mother. She is not who I know her to be". ${ }^{39}$ This suggests that the depersonization that accompanies Alzheimer's 
disease is not restricted to the sphere of the patients but often have social sequelae. In addition to this, families and proxies of AD patients confront difficult decisions related to eating problems and recurring infections ${ }^{40}$ and medical conditions such as aspiration pneumonia, pyelonephritis or other upper urinary tract infection and septicemia. ${ }^{41}$

On the other hand, care givers are not spared of the burdens of Alzheimer's. It is reported that they may become sleepless worrying about the possibility of their patients wandering off or engaging in activities that may endanger them. This is partly responsible for the high rate of depression diagnosed in AD care givers. ${ }^{42}$ Lastly, professionals in healthcare institutions also share in the social sequelae of Alzheimer's, especially in terms of the high rate of burn out which has been observed in this group. ${ }^{43}$ Finally, the lost productivity and clinical care associated with AD as at 2002 was estimated $\$ 61$ billion per annum. ${ }^{44}$ Against this background, the last part of this paper examines a care ethics approach to the vulnerabilities o Alzheimer's.

Care Ethics \& Alzheimer's Disease: Persons with AD need palliative interventions focused on relief of suffering, pain control and comfort. ${ }^{45}$ Although this inevitably puts AD patients in states of contextual vulnerability, such a scenario runs contrary and counter to the western Cartesian conception of the body in terms of rational capacities. ${ }^{46}$ Yet, the individual vulnerability inherent in AD has at its core a cognitive component which challenges claims to intactness of autonomy. Indeed, if being autonomous is not completely built on the fabric of individualism and a congeries of care networks foster security, wellbeing and wellness from cradle to the grave, ${ }^{47}$ then the superimposed loss in autonomy associated with Alzheimer's necessitates some supportive care. Because care ethics subsumes both action and dispositional support, it embeds the means of showing and demonstrating solidarity to AD patients. Transplanted to the context of CE, solidarity as the collective action and unity of a group in terms of seeking cooperative action $^{48}$ implies that family, care givers and health professionals need to provide the exigent rallying point for meeting the varied needs of AD patients. This section engages this as well as some of the implications.

Care Ethics vis-à-vis the Vulnerabilities of Alzheimer's Disease: The human condition of varying vulnerabilities and frailties usually provoke a sense of compassion from those around the sick (such as family, friends and/or healthcare professionals) who consequently act in ways that foster recovery. The capacity of CE to situate moral behavior via inter-personal relationships and engage contextual and relational sensitivity $^{49}$ suggests its relevance in relation to the vulnerabilities associated with AD. Indeed, if human beings are existentially active and passive seekers and givers of care, it would be expected that AD patients readily respond to care while family members, care givers and professionals readily furnish this. However, how this plays out may be shaped by context. For instance, within the western autonomy-driven healthcare, it has been consistently observed that patients with Alzheimer's exhibit defensive behaviors, resisting specific clinical interventions such as tubes and the use of mechanical 
restraints. ${ }^{50}$ However this may be missing or minimal in communitarian-oriented societies such as in Africa and Asia.

As a set of values as well as practice, care embeds having some idea of what an other can and should become; ${ }^{51}$ thereby facilitating the realization of potentialities. This again offers an avenue through which some of the lost autonomies and dignity of AD patients may be taken up and expressed by those around them. Indeed, the normative framework of CE offers a moral parameter for teasing out delicate boundaries between obligationbased ethics and responsibility-based ethics. Hence, the depersonalized realm of asking "what obligations do I have to patient X with AD?" may be readily transcended while entering into the humane sphere of seeking "how can I help patient X with AD?" This underscores the idea that the ends of caring include seeking ways to engage our common vulnerabilities. In other words, since humans as individuals and social beings are trapped within the human condition with all its barrage of limitations, the instinct of care has either evolved or been created to foster ways of circumventing our frailties. But since different societies express care in different ways, how CE may ultimately engage the ethical issues associated with AD will be context-dependent.

Some Implications for Alzheimer's Disease Care: It has been suggested that health policy research is essential to move advanced dementia care forward. A primary goal of such research should be to identify policies that incentivize cost-effective and evidencebased care without comprising the quality of palliative care provided to these vulnerable class of patients. ${ }^{52}$ Although this connotes a move towards exploring better ways of caring for $\mathrm{AD}$ patients, the materialistic conception of human experiences dominant in the western context ${ }^{53}$ continues to nudge patients towards seeking the "easy way out" through advance directive request for euthanasia and physicians-assisted suicide. This is partly driven by the economic burden of rationing and prolonging life via medical technology, ${ }^{54}$ but is morally problematic due to its tendency to commoditize human life.

On the other hand, the different socio-cultural context which operates in the other contexts will probably delay or continue to forestall the tide of public policy favoring the legalization of euthanasia and PAS for AD patients in general and AD patients in particular. In Nigeria, for instance, it has been reported that the prevalence of Alzheimer's is not as high as that that found in similar ethnic groups due to differing socio-cultural networks. ${ }^{55}$ Indeed, Ogunniyi recently reported that while aging populations in certain groups such as the Yoruba in Nigeria may have the consistent pattern of amyloid deposits in brain tissue, this does not correlate with the extent of symptoms. One possible explanation is the more socially integrated and connected way of living, which naturally facilitates bonding and reciprocal obligations. ${ }^{56}$

Concluding Remarks: This paper has teased out some of the vulnerabilities associated with Alzheimer's disease. It argues that the localization of care ethics around family, friends, colleagues and the public sphere ${ }^{57}$ as well as its rejection of the atomistic notion 
of the self $f^{58}$ offers a useful approach for engaging some of the contextual vulnerabilities of AD.

\section{References}

1. ter Meulen, R. "Ethics of Care," in The Sage Handbook of Health Care Ethics, ed. Chadwick, R., ten Have, H. and Meslin, E.M. (SAGE, 2011). p. 39-40.

2. ten Have, H. and Purtilo, R.B. "Introduction: Historical Overview of a Current Global Challenge," in Ethical Foundations of Palliative Care for Alzheimer Disease, ed. Purtilo, R.B and ten Have, H. (Johns Hopkins University Press, 2004). Pp. 1-3.

3. O'Brien, R.L. "Darkness Cometh: Personal, Social, and Economic Burdens of Alzheimer's Disease," in Ethical Foundations of Palliative Care for Alzheimer's Disease, ed. Purtilo, R.B and ten Have, H. (Johns Hopkins University Press, 2004). p. 8

4. ter Meulen, "Ethics of Care." p. 42.

5. Dekkers, W.J.M."Autonomy and the Lived Body in Cases of Severe Dementia," in Ethical Foundations of Palliative Care for Alzheimer Disease, ed. Purtilo, R.B and ten Have, H. (Johns Hopkins University Press, 2004). p. 117.

6. Brumback, R.A. "Neuropathology and Symptomatology in Alzheimer Disease," in Ethical Foundations of Palliative Care for Alzheimer Disease, ed. Purtilo, R.B and ten Have, H. (Johns Hopkins University Press, 2004). Pp. 24-35.

7. Gauthier, S., Cummings, J., Ballard, C., Brodaty, H. Grossberg, G. Robert, P. et al. "Management of Behavioral Problems in Alzheimer's Disease," International Psychogeriatrics 22, no. 03 (2010). p. 347.

8. Bennahum, D.A. "The Clinical Challenge of Uncertain Diagnosis and Prognosis in Patients with Dementia," in Ethical Foundations of Palliative Care for Alzheimer Disease, ed. Purtilo, R.B and ten Have, H. (2004). p. 48.

9. Mitchell, S.L, Betty S.B., Mary, E., Laura C.H., Susan C.M., Greg A.S. et al. "Advanced Dementia: State of the Art and Priorities for the Next Decade," Annals of Internal Medicine 156, no. 1 Part 1 (2012). p. 45.

10. Hugh H.C., Ogunniyi, A. Hall, K.S., Baiyewu, O. Unverzagt, F.W. and Gureje, O. et al. "Incidence of Dementia and Alzheimer Disease in 2 Communities: Yoruba Residing in Ibadan, Nigeria, and African Americans Residing in Indianapolis, Indiana" Journal of American Medical Association 285, no. 6 (2001). Pp. 739-740.

11. Wennström, M. and Nielsen, H.M. "Cell Adhesion Molecules in Alzheimer's Disease," Degenerative, Neurological \& Neuromuscular Disease 2 (2012). Pp. 65-67.

12. Hardy, J. and Selkoe, D.J. "The Amyloid Hypothesis of Alzheimer's Disease: Progress and Problems on the Road to Therapeutics," Science 297, no. 5580 (2002). Pp. 353-354.

13. ten Have and Purtilo, "Introduction: Historical Overview of a Current Global Challenge." p. 3.

14. Springer, S.P. and Deutsch, G. Left Brain, Right Brain: Perspective from Cognitive Neuroscience, 3rd ed. (WH Freeman and Company New York, 1989). p. 200

15. Brumback, "Neuropathology and Symptomatology in Alzheimer Disease." p. 25.

16. ter Meulen, "Ethics of Care." p. 48.

17. Dekkers, "Autonomy and the Lived Body in Cases of Severe Dementia." Pp. 115-116.

18. Woods, S. "Respect for Autonomy and Palliative Care," in Euthanasia: European Perspectives, ed. ten Have, H. and Clarke, D. (2005). p. 146. 
19. Dworkin, G. The Theory and Practice of Autonomy (Cambridge University Press, 1988). pp. 40-41.

20. Kelly, D.F. Medical Care at the End of Life: A Catholic Perspective (Georgetown University Press, 2006). p. 29.

21. Woods, "Respect for Autonomy and Palliative Care." p. 150.

22. Dekkers, "Autonomy and the Lived Body in Cases of Severe Dementia." Pp. 119-121.

23. Woods, "Respect for Autonomy and Palliative Care." Pp. 153, 158.

24. Dekkers, "Autonomy and the Lived Body in Cases of Severe Dementia." p. 118.

25. Kaufer, D.I., Cummings, J.L., Christine, D., Bray, T., Castellon, S., and Masterman, D. et al "Assessing the Impact of Neuropsychiatric Symptoms in Alzheimer's Disease: The Neuropsychiatric Inventory Caregiver Distress Scale," Journal of the American Geriatrics Society (1998). Pp. 1078-1080; ten Have and Purtilo, "Introduction: Historical Overview of a Current Global Challenge." p.1.

26. O’Brien, "Darkness Cometh: Personal, Social, and Economic Burdens of Alzheimer's Disease." p.9.

27. Neves, M.P. "Respect for Human Vulnerability and Personal Integrity," in The Unesco Universal Declaration on Bioethics and Human Rights: Background, Principles and Application, ed. ten Have, H. and Jean, M. (UNESCO, 2009). Pp. 158-162.

28. Afolabi, M.O. "A Vulnerability/Solidarity Framework for a Global Ethic: Historical \& Contemporary Applications," Revista Română de Bioetică 13, no. 1 (2015). p. 45.

29. O’Brien, "Darkness Cometh: Personal, Social, and Economic Burdens of Alzheimer's Disease." p. 9.

30. Gauthier et al., "Management of Behavioral Problems in Alzheimer's Disease." p.350.

31. Dees, M. et al., "Unbearable Suffering of Patients with a Request for Euthanasia or PhysicianAssisted Suicide: An Integrative Review," Psycho-Oncology 19, no. 4 (2010). p. 250

32. ten Have, H. "Euthanasia: Moral Paradoxes," Palliative Medicine 15, no. 6 (2001). Pp. 505-506.

33. Gordijn, B., Crul, B. and Zylicz, Z. "Euthanasia and Physician Assisted Suicide," in The Ethics of Palliative Care European Perspectives, ed. ten Have, H. and Clarke, D. (Open University Press, 2002). Pp. 232-233.

34. Morrissey, M.B.Q. Suffering Narratives of Older Adults: A Phenomenological Approach to Serious Illness, Chronic Pain, Recovery and Maternal Care (Routledge, 2014). p. 10.

35. ten Have, H. "Palliative Care," in The International Encyclopedia of Ethics, ed. Hugh LaFollette (Blackwell Publishing, 2013).

36. Mitchell, S.L. "Palliative Care of Patients with Advanced Dementia," in UptoDate.

37. Dekkers, "Autonomy and the Lived Body in Cases of Severe Dementia." p. 117.

38. Bennahum, "The Clinical Challenge of Uncertain Diagnosis and Prognosis in Patients with Dementia." Pp. 49-51.

39. Hinton, W.L. and Levkoff, S."Constructing Alzheimer's: Narratives of Lost Identities, Confusion and Loneliness in Old Age" Culture, Medicine and Psychiatry 23, no. 4 (1999). p. 453.

40. Mitchell et al., "Advanced Dementia: State of the Art and Priorities for the Next Decade." p. 46. 41. Mitchell, "Palliative Care of Patients with Advanced Dementia."

42. O’Brien, "Darkness Cometh: Personal, Social, and Economic Burdens of Alzheimer's Disease." Pp. 10-12.

43. Gauthier et al., "Management of Behavioral Problems in Alzheimer's Disease." p. 450. 
44. O’Brien, "Darkness Cometh: Personal, Social, and Economic Burdens of Alzheimer's Disease." p.13.

45. ten Have and Purtilo, "Introduction: Historical Overview of a Current Global Challenge." p.4.

46. Kissell, J.L. "The Moral Self as Patient," in Ethical Foundations of Palliative Care for Alzheimer Disease, ed. Purtilo, R.B and ten Have, H. (Johns Hopkins University Press, 2004), p. 133.

47. Robinson, F. The Ethics of Care: A Feminist Approach to Human Security (Temple University Press, 2011). p. 161.

48. Mechtraud, S. "Durkheim's Concept of Solidarity," Philippine Sociological Review (1955). pp. 23,27

49. Vanlaere, L. and Gastmans, C. "A Personalist Approach to Care Ethics," Nursing Ethics 18, no. 2 (2011). P. 162

50. Dekkers, "Autonomy and the Lived Body in Cases of Severe Dementia." p. 116.

51. Groenhout, R.E. Connected Lives: Human Nature and an Ethics of Care (Rowman \& Littlefield, 2004). p. 37.

52. Mitchell et al., "Advanced Dementia: State of the Art and Priorities for the Next Decade." p. 48.

53. Marcum, J.A. "Reflections on Humanizing Biomedicine," Perspectives in Biology and Medicine 51, no. 3 (2008). p. 398.

54. Kelly, D. Medical Care at the End of Life: A Catholic Perspective. pp. 128-129; ten Have and Welie, Death and Medical Power p. 158.

55. Gureje, O., Rodenberg, C.A., Musick, B.S. and Adeyinka, A. "Prevalence of Alzheimer's Disease and Dementia in Two Communities: Nigerian Africans and African Americans," American Journal of Psychiatry 152, no. 10 (1995). Pp. 1585-1588

56. Ogunniyi, A.O. "Teasing out Dementia Risk Factors: From Field to Bench," in Unibadan Conference on Biomedical Research (Nigeria, 2014).

57. Osuji, P.I. African Traditional Medicine: Autonomy and Informed Consent, vol. 3 (Springer, 2014). p. 58.

58. Edwards, S.D. "Is There a Distinctive Care Ethics?" Nursing ethics 18, no. 2 (2011). p. 187.

Conflict of Interest: Declared None 